\title{
ICT Innovation and Local Economy: Mobile Game as a Tourist Attraction
}

ARTICLE in SCANDINAVIAN JOURNAL OF HOSPITALITY AND TOURISM • OCTOBER 2013

Impact Factor: 0.63 · DOI: 10.1080/15022250.2013.772770

READS

29

2 AUTHORS, INCLUDING:

Teemu Makkonen

University of Surrey

21 PUBLICATIONS 17 CITATIONS

SEE PROFILE 
ICT Innovation and Local Economy: Mobile Game as a Tourist

Attraction

Teemu Makkonen ${ }^{12} \&$ Timo J. Hokkanen ${ }^{3}$

${ }^{1}$ Pan-European Institute, Turku School of Economics at the University of Turku, Turku, Finland

2 Department of Geosciences and Geography, University of Helsinki, Finland

${ }^{3}$ Centre of Economic Development, Transport and the Environment for North Karelia, Joensuu, Finland

Correspondence address: Teemu Makkonen, Pan-European Institute, Turku School of Economics at the University of Turku, Rehtorinpellonkatu 3, FI-20014 Turku, Finland, teemu.makkonen@utu.fi

Running title: ICT Innovation and Local Economy

This is an Accepted Manuscript of an article published by Taylor \& Francis Group in Scandinavian Journal of Hospitality and Tourism on 11 Mar 2013, Vol. 13, No. 3, pp. 257-268. Available online:

http://www.tandfonline.com/doi/abs/10.1080/15022250.2013.772770 


\begin{abstract}
Innovations are considered crucial in boosting the growth of regions. Similarly, tourism is an important regional development tool especially in areas with no industrial potential. Research on tourism innovation has been scarce until the very recent years and the local economic impacts of innovation in tourism studies remain unexplored. This study addresses the innovative ICT application, a mobile game, and its significance as a tourist attraction in Pielinen Museum in Lieksa, a peripheral town in Eastern Finland. Pielinen Museum has a substantial effect on Lieksa municipality economy and the average visitor expenditure is substantially higher than expected based on previous studies on other local attractions. We conclude, however, the game is not known by general public to attract visitors. From museum's point of view the innovation will not have extensive influence as a standalone, one time effort. It needs better integration into museum's general public image and continuous support and updating for both contents and technique. Extensive networking with existing regional visitor attractions for increasing the publicity without excessive costs is highly advisable.
\end{abstract}

Keywords: Attraction, ICT Innovation, Tourism, Visitor Expenditure

\title{
Introduction
}

Innovations are considered of utmost importance to the growth of regions (Howells, 2005). Similarly, tourism is frequently cited as one of the fastest growing industries in the world (Hall \& Page, 1999; Neto, 2003). Tourism has gained increasing amount of attention as a development tool, especially in rural areas where the conditions for success are relatively weaker for many other economic activities. It is evident that tourism can generate significant or at least fair amounts of outside 
expenditure into the local economy, thus revitalizing the local economic structure (Saarinen, 2003; Rinne \& Saastamoinen, 2005). Still, research on tourism innovations has been limited up until recently whereby local economic impacts of innovation in the field of tourism are still unexplored (Orfila-Sintes et al., 2005; Sørensen, 2007).

This paper examines the local economic impacts of tourism with the expenditure method of Nordic model of tourism. The Nordic model is a commonly used methodology in Finland to collect data for estimating impacts of tourism on the local economy. The innovative ICT application, a mobile phone game named LieksaMyst, addressed here has been set up in the Pielinen Museum in Lieksa, one of the peripheral towns of Eastern Finland. LieksaMyst offers a pervasive learning space bridging the physical and virtual worlds for fun and education. Innovation in tourism sector is usually an application originally invented in other sector, which is successfully adapted to meet the needs of tourists (Weidenfeld et al., 2010). Accordingly, although mobile phone games are not new to the world, the case addressed here matches the description of an innovation as a new marked-based application of an existing product. The town itself has been experiencing outmigration and unemployment; for Lieksa, tourism represents one of the most important economic activities with significant growth potential. The main research questions, from which some managerial implications are drawn, of this study are: 1) does the Pielinen Museum have a significant economic impact (income and employment) on the local economy of Lieksa and 2) does the mobile game (innovation) work as a significant tourist attraction? 


\section{Innovation, Rural Development and Tourism Attractions}

Although innovation holds great potential for tourist destinations to attract visitors (Pechlaner et al., 2005), many authors have noted that there is a general lack of academic empirical research and precise definition of innovation in the service oriented tourism industry (Hjalager, 2002; Orfila-Sintes et al., 2005; Sørensen, 2007; Sundbo et al., 2007; Hall \& Williams, 2008). Nevertheless, tourism firms and destinations operate in a competitive demand-driven sector: firms' and destinations' competitiveness depends on their innovativeness in achieving lower costs, higher quality outputs and new products and services (Sundbo et al., 2007; Jacob et al., 2010). Thus, the innovativeness of tourism sector has gained an increasing amount of attention from academics in the very recent years [for an extensive overview on the subject see Hjalager (2010)]. Still, innovations in tourism are predominantly linked to innovative efforts undertaken in other sectors i.e. in general tourism businesses have been mainly imitators and adaptors rather than innovators (Weidenfeld et al., 2010; Camisón \& Monfort-Mir, 2012).

As the economic impacts of tourism are growing steadily, tourism has been increasingly viewed as a tool for urban (Law, 1992; Plaza \& Haarich, 2009) and regional development (Saarinen, 2003; Puhakka, 2008). In the local level, tourism is used to diversify the economic base of communities as it positively impacts on income- and employment. In particular, tourism is extremely valuable for rural and peripheral areas where employment opportunities are weak and where the services cannot be maintained only with the purchasing power of the local inhabitants. Indeed, in many remote or underdeveloped regions, tourism represents practically 
the only form of viable economic activity having realistic growth prospects in the future (Saarinen, 2007; Kauppila et al., 2009). Moreover, tourism has many sided direct, indirect and derived impacts on the local economy (Figure 1), as it affects also industries, which are not directly connected to catering the needs of tourists. Also the local administration benefits from tourism through taxation. Of course certain proportion of the incomes and employment will always 'leak' out form the regional economy (Saarinen, 2003), but one can speak of multiplicative impacts of tourism.

\section{"Insert Figure 1 here"}

Still, not every rural locale in need of employment and income generation is a candidate for tourism (Fleischer \& Felsenstein, 2000; Toivonen, 2002); there has to be something special to lure the tourists to the region i.e. attractions (Lew, 1987; Leiper, 1990; Holloway, 2006). In this study the division made by Leiper (1990) into primary, secondary and tertiary nucleus of tourism attractions is acknowledged. A primary nucleus is the most important reason for tourist to visit a region, a secondary nucleus is known to a person pre-visit, but is not that significant in decisions about the itinerary, and a tertiary nucleus is an attribute unknown pre-visit, but discovered by the tourist after arriving in a destination region.

\section{Empirical Backgrounds}

The Nordic Model of Tourism

Nowadays probably the most commonly used method for estimating the local economic impacts of tourism in Finland, is the Nordic model (or Nordic method). 
The Finnish Tourist Board (Matkailun edistämiskeskus) published instructions for the utilization of the model already in 1983 and since then many studies of the impacts of tourism in Finland have applied the Nordic model (Saarinen, 2003; Rinne \& Saastamoinen, 2005; Huhtala et al., 2009). The Nordic model is employed to measure the economic and employment impacts of tourism and it can be divided into two discrete parts; expenditure and receipts methods, which can be used separately or together as complementary to each other. The expenditure method is used to survey the spending of tourists in a region with the help of structured questionnaires (or interviews) distributed on site while the receipts method is used to estimate the share of tourism revenue and employment of firms using structured questionnaires posted to firms in the study region believed to cash in on tourism. However, the results attained by using the model have also been criticized, as the model permits numerous variations, to be dubious in their reliability, repeatability and comparison (Vuoristo \& Arajärvi, 1990; Paajanen, 1993; 1994). Still, the Nordic model has proven to be a valuable tool for evaluating the economic impacts of tourism.

\section{Previous Studies of the Economic Impacts of Tourism in Lieksa}

Lieksa is a small, rural and sparsely populated (population ca. 12500 ; population density ca. 3.7 inhabitants $/ \mathrm{km}^{2}$; in 2012) town in the eastern part of Finland in North Karelia, situated along the Finnish-Russian border (Figure 2). Tourism has a prominent role in the service-oriented economy of Lieksa as it is home for Koli (one of the most popular Finnish national parks) as well as Patvinsuo national park and Ruunaa hiking area. Since the deep recession of the Finnish economy in the early 
1990s, Lieksa has suffered from structural changes, unemployment and outmigration. Considering the difficulties faced by peripheral economies, the impact of tourism as a source for income and employment is of particular significance for Lieksa in keeping the town lively and attractive.

\section{"Insert Figure 2 here"}

Table 1, summarising the result of a survey conducted by the Finnish authorities in charge of the nature sites shows that roughly $75000 €$ of direct gross income from tourism are enough to create one job in Lieksa. From an earlier study by Eisto (2003) on the economic impact of Ruunaa hiking area to the economy of Lieksa, it can be calculated that this figure would have had a range between 83 300-116700€. However, the impacts measured in the study were suggestive: Eisto (2003) estimated that the gross income impact of Ruunaa hiking area to the economy of Lieksa was between 2.5-3.5 million $€$ which resulted into employment effect of about 30 person years. It was estimated that about 60000 visitors came to Ruunaa hiking area and an average visitor spent about $50 €$ during the stay in Lieksa. The median for visitors in Patvinsuo national park was exactly the same: $50 €$ per person per trip (Heikkilä, 2008).

"Insert Table 1 here"

To sum up, tourism is a vital source of income and employment in Lieksa: previous studies have shown that Koli and Patvinsuo national parks and Ruunaa hiking area 
make an important contribution to the local economy and work as significant tourism attractions.

\section{The Pielinen Museum and LieksaMyst}

The Pielinen Museum, depicting the rural way of life and peasant culture in Eastern Finland during the centuries so far, is the second largest open air museum in Finland and it is situated in the centre of Lieksa. The museum had about 8200 visitors in 2009 and 8600 in 2010 (Pielisen Museo, 2011). During the summer season the museum offers an opportunity to experiment a mobile game (a wireless web has been set up at the museum to allow the game play and visitors are provided with mobile phones, with the game installed), called LieksaMyst. The game has been designed and developed for all user groups regardless of age and gender by UbiqueLab team from Educational Technology Research Group at the University of Eastern Finland together with the curators and visitors of the museum during 20072010. The purpose of the game is to bridge the physical- and virtual worlds by offering a new way of learning things using two story based games. The developers consider the merging of the physical and virtual worlds as ground-breaking (Islas Sedano et al., 2011). Even more so, when considering that virtual games are rarely used in museums (Islas Sedano et al., 2012). The first storyline, situated in the end of the $19^{\text {th }}$ century, challenges the visitor to learn about the daily chores of a housewife named Anna and the second, situated in the 1930s, illustrates the life of Jussi, a lumberjack working on a nearby logging site (Laine et al., 2010). In essence, these virtual hosts request players to identify objects, found in the physical environment where the player is embedded, they need to execute their daily activities. 


\section{Survey Method and Sample}

The expenditure method of Nordic Model of Tourism (Matkailun edistämiskeskus, 1983; Rinne \& Saastamoinen, 2005; Huhtala et al., 2009) was used here to survey the spending of tourists in Lieksa using structured questionnaires. Questionnaires included questions concerning the background information of respondents (e.g. sex, year of birth, travel group information and place of residence), accommodation, information sources, other attractions, spending of the respondents and specific questions concerning the museum and LieksaMyst (e.g. satisfaction and impact on the choice of destinations) (Pasanen et al, 2009). The questionnaires (available in Finnish and in English) were distributed on site by the employees of the museum, but without significantly 'marketing' the questionnaire. Thus, every visitor was a potential respondent, but no one was 'forced' to answer leaving us with a modest turnout. Altogether, 141 answers were collected between summer of 2010 to the fall of 2011. Since we allowed answers to be were given on behalf of a visitor group, the answers depict the views and expenditure of 375 visitors.

Data from previous studies were employed in the calculations, when generalizations concerning the overall economic impacts are being made. First, we estimated according to existing literature, that the multiplicative income impacts vary between 1.05 and 1.5, whereas the multiplicative impacts of tourism employment have a range from 1.01 to 1.07 (Vuoristo \& Arajärvi, 1990; Rinne \& Saastamoinen, 2005). Second, we generalise that roughly $75000 €$ of direct gross income from tourism is enough to create one job in Lieksa (see Table 1). Third, we excluded a percentage value of five of the respondents from the analysis as 'locals' according to the 
background information of the respondents. Keeping in mind the limitations of small samples, the data was suitable in statistical terms for standard t-test and Spearman's correlation test, which we employed when analyzing the impacts of basic trip characteristics on the spending of visitors.

\section{Results}

About $60 \%$ of the respondents were female and the average correspondent was aged 43. The average group size of the respondents was $4-5$ persons and the average duration of the trip to Lieksa was 2-3 days, in which time the respondents, in general, also visited (at least) one other tourist attraction in Lieksa. The majority of the correspondents were mainly from other parts of Eastern Finland, the Helsinki metropolitan region or abroad (especially from Germany and France) (Figure 3). The basic trip characteristics, except for group size, including distance from residence, length of stay and accommodation type highly influence the amount of money spent in a trip. The results indicate (t-value $=2.938 ; \mathrm{df}=68 ; \mathrm{p}$-value $=0.005)$ that the visitors from other parts of Finland or abroad spent more money (on average $122 €$ per person) during their stay in Lieksa compared to visitors from Eastern Finland (on average $66 €$ per person). Similarly, an increase in the length of stay (Spearman's correlation coefficient $=0.605 ; \mathrm{p}$-value $<0.001$ ), in particular when staying in a hotel, rental cottage or farm accommodation, or in the number of other destinations visited (Spearman's correlation coefficient $=0.226 ; \mathrm{p}$-value $=0.015$ ) are related to higher tourism income. However, most of the visitors staying overnight spent them with friends or relatives or in their own summer cottages (Figure 3). 


\section{"Insert Figure 3 here"}

The Pielinen Museum was the primary target of the trip for $13 \%$ of the respondents. Most commonly the museum was a planned site to visit during the trip (57\% of the respondents), but not the only one, and for some the museum was an indiscriminate visit decided on the spot (30\% of the respondents). All in all the visitors where satisfied with the museum [customer satisfaction score (max. 5): 4.4]. For most the museum was familiar from earlier visits or they had heard from it from friends and relatives. Brochures, and to a lesser degree the Internet, where also considered as important sources of information retrieval about the museum.

The average out-of-town visitor to the museum spent about $100 €$ (93 $€$ per day, when weighted according to the length of stay) during their stay in Lieksa. Most of the expenditure was spent on groceries, retail trade and accommodation (Table 2). The fact that most overnight stays are spend in locations 'free-of-charge', i.e. at friends and relatives or at own summer cottages, lowers the significance of expenditure spent on accommodation.

\section{"Insert Table 2 here"}

From table 2 it is possible to calculate broader estimations of the economic impact of the Pielinen Museum on the local economy of Lieksa. According to the about 8500 annual visitors it can be estimated that the tourists visiting the museum have an annual gross expenditure effect of ca. $800000 €(5 \%$ of visitors were excluded as 'locals') in the local economy of Lieksa. The gross employment effect, in addition to 
the staff of the museum, is 11 person-years (according to the postulated $75000 €$ per person-year). When the museum is considered as the primary target of the visit to Lieksa the corresponding figures are ca. $105000 €$ and 1 person-year. When taking into account the multiplicative impacts, the gross expenditure (lower bound 1.05; upper bound 1.5) and employment (lower bound 1.01; upper bound 1.07) figures have a range of ca. $850000-1200000 €$ and 11-12 person-years or when the museum was the primary target ca. 110 000-160 $000 €$ and 1-2 person-year(s).

The impact of the mobile game to visit the museum was, however, negligible. The Internet was the major source from where the visitors had learned about the existence of the mobile game. However, only a minority of the respondents had heard about the possibility to try out the mobile game in the museum. From the respondents who had a prior knowledge of the game, only a few acknowledged that it had an impact on the choice of destinations to visit (Figure 4).

"Insert Figure 4 here"

\section{Discussion and implications}

According to Leiper's (1990) typology, the museum was a primary or secondary nucleus of attractions for most of the respondents as it was the primary reason for or among the planned destinations of the visit. The museum is one of the significant tourism attractions of Lieksa. However, almost one third of the visits of respondents were unplanned stops along the way (tertiary nucleus) highlighting the importance of on-site stimuli (Hwang \& Fesenmaier, 2011). Compared to previous studies 
conducted in Lieksa, the average visitor expenditure (100€) is significantly higher than expected vis-à-vis to the $50 €$ estimated by Eisto (2003) and Heikkilä (2008). When considering the overall gross economic and employment impacts, the results are modest in comparison to the large nature sites of Lieksa (Table 1), because of their sheer volume of tourists, but proportionally as a tourist attraction the Pielinen Museum does make a contribution to Lieksa's local economy. This is much due to the average visitor profile of the museum; culture sites usually attract more middleaged and senior visitors, with high purchasing power, compared to nature sites (Bansal \& Eiselt, 2004; Pouta et al., 2006). The presented financial estimations might be affected by the fairly small sample size, but both of the study years showed similar results, and also the structure of clientele supported them.

The impact of trip-related factors (length of stay, number of other attractions visited etc.) was as expected: all in all, the case of Lieksa fits well in relation to other microanalyses of the impacts of independent variables on travel expenditure (Wang \& Davidson, 2010). The notion by Clarke (2005) of increasing visitor length of stay with additional attractions (and activities) and strengthening the networking (common marketing, funding bids etc.) between these attractions should be taken (more) into consideration in Lieksa to help gain from the arising synergies between nature-based and cultural attractions. As psychological and destination-related factors influence travel expenditures, close attention should be paid on the attractive exhibition and event management and the range and quality of activities available at the museum (Plaza \& Haarich, 2009; Wang \& Davidson, 2010); LieksaMyst should be a factor in this. 
According to our results, as of now the mobile game seems to have been without a larger audience, and the potential which it offers, underutilized. For the game to be considered as part of the museum attractiveness, a more active approach to marketing the mobile game might help. In particular, on spot marketing to signal the existence of the game in other tourist attractions within Lieksa and extensive marketing through the Internet are advisable, as the results of this study support both; the importance of the Internet in gaining knowledge of the attractions and the high proportion of tourists visiting multiple attractions during their stay in Lieksa.

LieksaMyst is intended for all user groups, but the current average museum visitor, a middle-aged woman, is not necessarily interested in mobile games (Williams et al., 2008). It is likely that the wide-ranging application of the game would require a different type of clientele. Moreover, when considering the fast pace of technological development and mobile game contents, the innovation process has already taken too long from initial 'launch' to wide-range dissemination, as the use of cellular phones are, as it is, outdated compared to 'smart phones' and tablet PCs (White, 2010). This is not to say that the LieksaMyst wouldn't be a functional educational 'space', but to urge a more comprehensive way of planning tourist/visitor innovations and rural development. It seems that a mobile game has little to contribute to the overall development of tourism or visitor services in a municipality, when considered a separate attraction. Continuous updating of contents and technique as well as involving regional developers, tourism planning and marketing experts would increase structural support and improve chances to succeed. 


\section{Concluding Remarks}

The results show that visitors of the location itself (Pielinen Museum) have a considerable income and employment impact on the local economy of Lieksa. Networking between the nature-based and cultural attractions is advisable to allure travellers to visit more than just one local tourist destination. This would increase the length of stay and tourist income. The mobile game, however, is not a stand-alone significant tourist attraction, and it seems not to be well-known enough to draw in substantial number of visitors. A 'people will come' mind-set functions poorly in tourism: new products or services alone (no matter how exquisite or innovative) produce limited value for their possessors or the local economy without inclusion of a broader view of the local context in the development stage of the innovation. Codevelopment could ensure the build-up of supportive structures (funding, updates etc.) and integration of the innovation into the already present and strong tourism environment. Also marketing, in particular on the Internet, should be developed and enhanced. We conclude that although a single innovation is interpreted and discussed here through the regional case of Lieksa, the results, however, bear a wider relevance for innovation management and tourism planning by showing the potential vulnerability of an innovation without complete integration into structures maintaining it and ensuring its further development.

Acknowledgements: This work is a part of project 127213 funded by the Academy of Finland. An earlier version of this paper with preliminary results was presented in the $4^{\text {th }}$ International Conference for Entrepreneurship, Innovation and Regional Development held in Ohrid, Macedonia on May 2011. The authors would like to 
thank the city of Lieksa, especially Director of Education and Cultural Service Jarkko Määttänen, Director Liisa Eskelinen and the staff of the Pielinen Museum, for their support. The authors are grateful to Daisy Silvennoinen for language editing and to the Editors and anonymous referees for comments improving the paper. 


\section{References}

Bansal, H., \& Eiselt, H. A. (2004). Exploratory research of tourist motivations and planning. Tourism Management, 25, 387-396. doi:10.1016/S0261-5177(03)00135-3

Camisón, C., \& Monfort-Mir, V. (2012). Measuring innovation in tourism from the Schumpeterian and the dynamic-capabilities perspectives. Tourism Management, 33, 776-789. doi:10.1016/j.tourman.2011.08.012

Clarke, J. (2005). Effective marketing for rural tourism. In D. Hall, I. Kirkpatrick, \& M. Mitchell (Eds.), Rural tourism and sustainable business (pp. 41-62). Clevedon: Channel View Publications.

Eisto, I. (2003). Ruunaan retkeilyalueen kävijät ja paikallistaloudelliset vaikutukset. Metsähallituksen luonnonsuojelujulkaisuja A, 143.

Fleischer, A., \& Felsenstein, D. (2000). Support for rural tourism: Does it make a difference? Annals of Tourism Research, 27, 1007-1024. doi:10.1016/S01607383(99)00126-7

Hall, C. M., \& Page, S. J. (1999). The geography of tourism and recreation: Environment, place and space. London: Routledge.

Hall, C. M., \& Williams, A. M. (2008). Tourism and innovation. Abingdon: Routledge.

Heikkilä, A. (2008). Patvinsuon kansallispuiston kävijätutkimus 2007. Metsähallituksen luonnonsuojelujulkaisuja B, 87.

Hjalager, A-M. (2002). Repairing innovation defectiveness in tourism. Tourism Management, 23, 465-474. doi:10.1016/S0261-5177(02)00013-4

Hjalager, A-M. (2010). A review of innovation research in tourism. Tourism Management, 31,1-12. doi:10.1016/j.tourman.2009.08.012

Holloway, J. C. (2006). The business of tourism. New Jersey: Pearson Education.

Howells, J. (2005). Innovation and regional economic development: A matter of perspective. Research Policy, 34, 1220-1234. doi:10.1016/j.respol.2005.03.014, 
Huhtala, M., Vatanen, E., \& Berghäll, J. (2009). Kansallispuistomatkailun paikallistaloudelliset vaikutukset - menetelmien vertailu. Terra, 121, 285-299.

Hwang, Y-H., \& Fesenmaier, D. (2011). Unplanned tourist attraction visits by travellers. Tourism Geographies, 13, 398-416. doi:10.1080/14616688.2011.570777

Islas Sedano, C., Pawlowski, J., Sutinen, E., Naumanen M., Vinni, M., \& Laine T. (2011). Involvement of non-technical individuals in the design of successful digital games. IEEE Multidisciplinary Engineering Education Magazine, 6, 1-9.

Islas Sedano, C., Sutinen, E., Vinni, M., \& Laine T. (2012). Designing hypercontextualized games: A case study with LieksaMyst. Educational Technology \& Society, 15, 257-270.

Jacob, M., Florido, C., \& Aguiló, E. (2010). Environmental innovation as a competiveness factor in the Balearic Islands. Tourism Economics, 16, 755-764. doi:10.5367/000000010792278365

Kauppila, P., Saarinen, J., \& Leinonen, R. (2009). Sustainable tourism planning and regional development in peripheries: A Nordic view. Scandinavian Journal of Hospitality and Tourism, 9, 424-435. doi:10.1080/15022250903175274

Laine, T., Islas Sedano, C., Joy, M., \& Sutinen, E. (2010). Critical factors for technology integration in game-based pervasive learnings. IEEE Transactions of Learning Technologies, 3, 294-306. doi:10.1109/TLT.2010.16

Law, M. (1992). Urban tourism and its contribution to economic regeneration. Urban studies, 29, 599-619.

Leiper, N. (1990). Tourist attraction systems. Annals of Tourism Research, 17, 367-384. doi:10.1016/0160-7383(90)90004-B

Lew, A. (1987). A framework of tourist attraction research. Annals of Tourism Research, 14, 553-575. doi:10.1016/0160-7383(87)90071-5

Matkailun edistämiskeskus (1983). Matkailun tulo- ja työllisyysvaikutukset kunta/aluetasolla: tutkimusmenetelmä. Matkailun edistämiskeskus A, 36.

Metsähallitus, \& Metsäntutkimuslaitos (2009). Kansallispuistojen ja retkeilyalueiden kävijöiden rahankäytön paikallistaloudelliset vaikutukset. Vantaa: Metsähallitus. 
Neto, F. (2003). A new approach to sustainable tourism development: Moving beyond environmental protection. Natural Resources Forum, 27, 212-222. doi:10.1111/14778947.00056

Orfila-Sintes, F., Crespí-Cladera, R., \& Martínez-Ros, E. (2005). Innovation activity in the hotel industry: Evidence from Balearic Islands. Tourism Management, 26, 851-865. doi: 10.1016/j.tourman.2004.05.005

Paajanen, M. (1993). The economic impact analysis of tourism: A comparative study of the Nordic Model and the Tourist Economic Model. Helsinki School of Economics and Business Administration Working Papers, 35.

Paajanen, M. (1994). The economic interaction between tourists and tourism enterprises. Helsingin kauppakorkeakoulun julkaisuja B, 142.

Pasanen, K., Taskinen, H., \& Mikkonen, J. (2009). Impacts of cultural events in Eastern Finland - Development of a Finnish event evaluation tool. Scandinavian Journal of Hospitality and Tourism, 9, 112-129. doi:10.1080/15022250903119546

Pechlaner, H., Fischer, E., \& Hammann, E-M. (2005). Leadership and innovation processes - Development of products and services based on core competencies. Journal of Quality Assurance in Hospitality and Tourism, 6(3), 31-57. doi:10.1300/J162v06n03_03

Pielisen Museo (2011). Toimintakertomus 2010. Lieksa: Pielisen Museo.

Plaza, B., \& Haarich, S. (2009). Museums for urban regeneration? Exploring conditions for their effectiveness. Journal of Urban Regeneration and Renewal, 2, 259-271.

Pouta, E., Neuvonen, M., \& Sievänen, T. (2006). Determinants of nature trip expenditures in Southern Finland - Implications for nature tourism development. Scandinavian Journal of Hospitality and Tourism, 6, 118-135. doi:10.1080/15022250600658937

Puhakka, R. (2008). Increasing role of tourism in Finnish national parks. Fennia International Journal of Geography, 186, 47-58.

Rinne, P., \& Saastamoinen, O. (2005). Local economic role of nature-based tourism in Kuhmo municipality, Eastern Finland. Scandinavian Journal of Hospitality and Tourism, 5, 89-101. doi:10.1080/15022250510014363 
Saarinen, J. (2003). The regional economics of tourism in Northern Finland: The socioeconomic implications of recent tourism development and future possibilities for regional development. Scandinavian Journal of Hospitality and Tourism, 3, 91-113. doi:10.1080/15022250310001927

Saarinen, J. (2007). Contradictions of rural tourism initiatives in rural development contexts: Finnish rural tourism strategy case study. Current Issues in Tourism, 10, 96-105. doi:10.2167/cit287.0

Sørensen, F. (2007). The geographies of social networks and innovation in tourism. Tourism Geographies, 9, 22-48. doi:10.1080/14616680601092857

Sundbo, J., Orfila-Sintes, F., \& Sørensen, F. (2007). The innovative behaviour of tourism firms - Comparative studies of Denmark and Spain. Research Policy, 36, 88-106. doi:10.1016/j.respol.2006.08.004

Toivonen, T. (2002). Regional development of Finnish tourism at the end of the 1990s: Some considerations. Tourism and Hospitality Research, 3, 331-342.

Vuoristo, K-V., \& Arajärvi, T. (1990). Methodological problems of studying local income and employment effects of tourism. Fennia - International Journal of Geography, 168, $153-177$.

Wang, Y., \& Davidson, M. (2010). A review of micro-analyses of tourist expenditure. Current Issues in Tourism, 13, 507-524. doi:10.1080/13683500903406359

Weidenfeld, A., Williams, A. M., \& Butler, R. W. (2010). Knowledge transfer and innovation among attractions. Annals of Tourism Research, 37, 604-626. doi:10.1016/j.annals.2009.12.001

White, M. (2010). Information anywhere, any when: The role of the smartphone. Business Information Review, 27, 242-247. doi:10.1177/0266382110390651

Williams, D., Yee, N., \& Caplan, S. (2008). Who plays, how much and why? Debunking the stereotypical gamer profile. Journal of Computer-Mediated Communication, 13, 9931018. doi:10.1111/j.1083-6101.2008.00428.x 


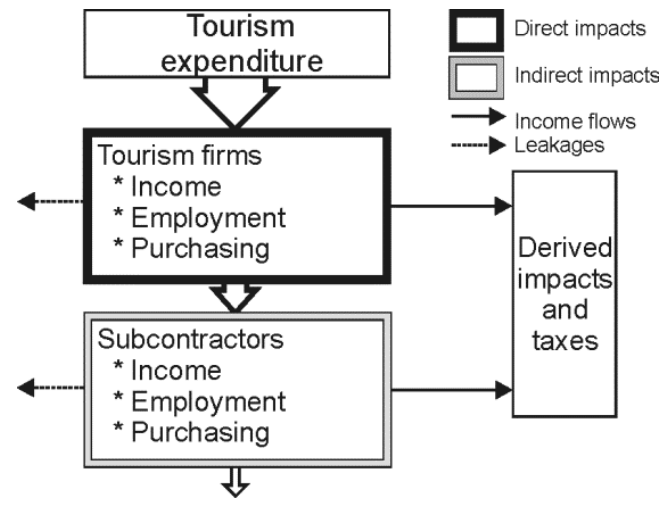

Figure 1. The local economic impacts of visitor expenditure (adapted from Rinne \&

Saastamoinen, 2005). 


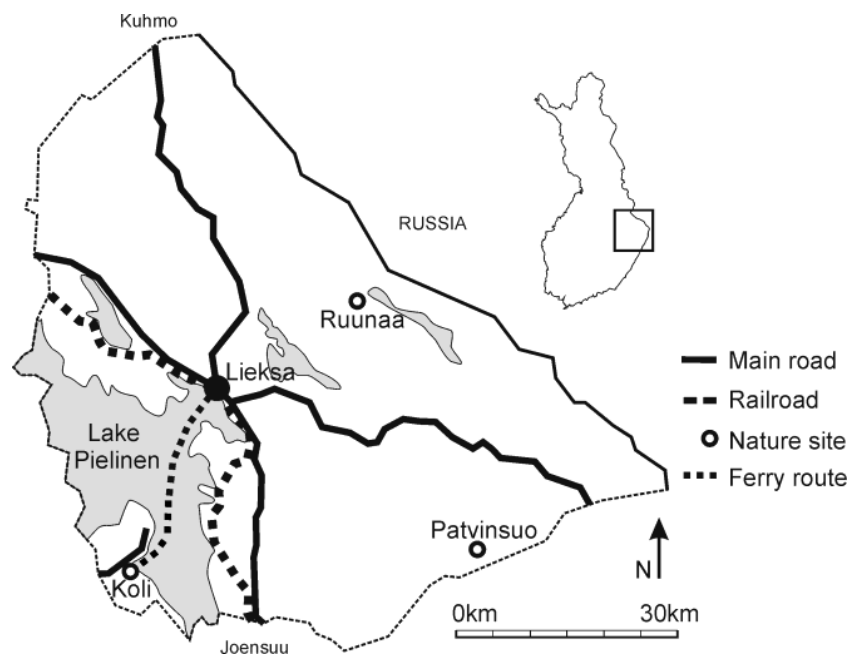

Figure 2. The map of Lieksa, Finland. 
Table 1. The local economic impacts of tourism in the primary nature sites of Lieksa

(Metsähallitus \& Metsäntutkimuslaitos, 2009).

\begin{tabular}{lcccc}
\hline \multirow{2}{*}{2008} & $\begin{array}{c}\text { Gross } \\
\text { income } \\
\text { impact } \\
\text { (mil. } € \text { ) }\end{array}$ & $\begin{array}{c}\text { Employment } \\
\text { impact } \\
\text { (person }\end{array}$ & $\begin{array}{c}\text { Job creation } \\
\text { (thousand } € \\
\text { per person } \\
\text { years)* }\end{array}$ & Visitors \\
\hline Koli National Park & $3,5 / 1,5$ & $47 / 19$ & $74 / 79$ & 110000 \\
Patvinsuo National Park & $0,6 / 0,2$ & $8 / 2$ & $75 / 100$ & 12194 \\
Ruunaa Hiking Area & $4,0 / 2,3$ & $53 / 31$ & $75 / 74$ & 87287 \\
\hline
\end{tabular}

* Total / when the area was the primary target of the trip. 

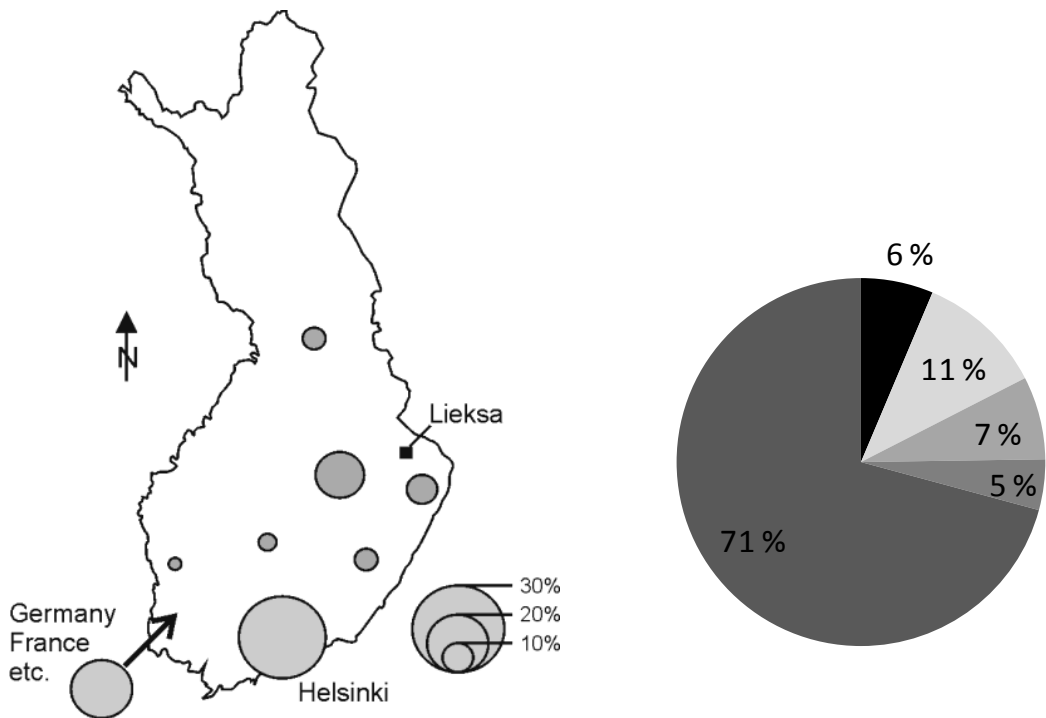

- Hotel

Rental cottage

Farm accom.

Campsite

Other

Figure 3. Left: Respondents' places of residence (ca. $5 \%$ of the respondents were from Lieksa) ( $n=126$ answers). Right: Type of accommodation according to overnights stays (the group 'other' includes staying at friends and relatives as well at own summer cottages) $(n=315$ overnight stays $)$. 


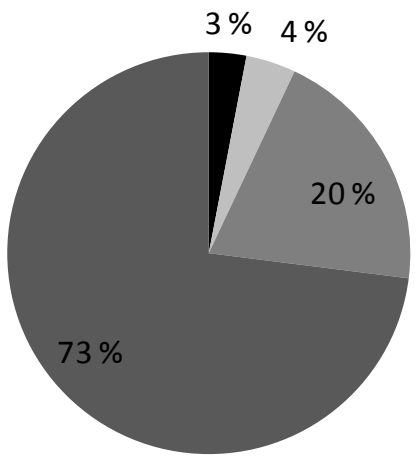

Primary reason for the visit

Prior knowledge of the game and some impact

Prior knowledge of the game, but no impact

No prior knowlege of the game

Figure 4. The impact of LieksaMyst in the choice to visit the Pielinen Museum ( $n=137$ answers). 
Table 2. The average expenditure of out-of-town respondents in Lieksa (€/person).

\begin{tabular}{lc}
\hline Refuelling and other station services & 21 \\
Local trips (e.g. bus, taxi, ferry) & 4 \\
Groceries and retail trade & 25 \\
Cafes and restaurants & 19 \\
Accommodation & 23 \\
Program- and recreational services (e.g. admission fees) & 7 \\
Other expenditure (e.g. equipment rents) & 1 \\
\hline Total & $\mathbf{1 0 0}$ \\
\hline
\end{tabular}

